\section{Research Square}

Preprints are preliminary reports that have not undergone peer review.

They should not be considered conclusive, used to inform clinical practice, or referenced by the media as validated information.

\title{
Negative Pressure Wound Therapy versus Gauze Dressings in Managing Open Fracture Wound of Lower Limbs: An Update Meta-Analysis of Randomized Controlled Trials
}

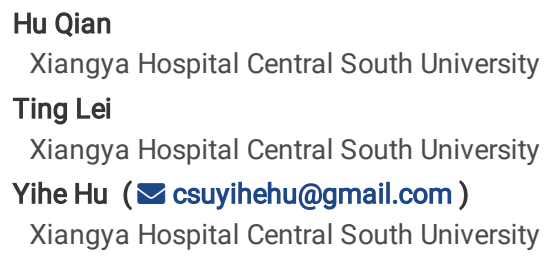

\section{Research Article}

Keywords: Open Fracture, Negative Pressure Wound Therapy, Standard Gauze Dressing, Meta-Analysis, RCTs

Posted Date: September 28th, 2021

DOI: https://doi.org/10.21203/rs.3.rs-942319/v1

License: @ (i) This work is licensed under a Creative Commons Attribution 4.0 International License. Read Full License

Version of Record: A version of this preprint was published at Foot and Ankle Surgery on April 1st, 2022. See the published version at https://doi.org/10.1016/j.fas.2022.03.012. 


\section{Abstract}

Introduction

Whether the negative pressure wound therapy (NPWT) is superior to standard gauze dressings in managing open fracture wounds of lower limbs still remains a controversy. Herein, we updated a meta-analysis only including RCTs to comprehensively compare the clinical efficacy of the two dressings.

Materials and methods

We searched various databases including PubMed, Web of Science, Medline, Clinicaltrial.gov and Cochrane Library to screen eligible RCTs. Data extraction was performed by two reviewers independently. The data analysis was carried out using the Review Manager 5.3 software.

Results

There were 10 RCTs, along with 2780 patients, eligible for meta-analysis. We found patients in the NPWT group showed lower overall infection rate (MD $=0.70$, $95 \% \mathrm{Cl}: 0.54-0.90, P=0.005)$, acute wound infection rate ( $\mathrm{MD}=0.35,95 \% \mathrm{Cl}: 0.16-0.77, P=0.009)$ and shorter hospital stay (MD $=24.00,95 \% \mathrm{Cl}: 6.82-$ 84.46, $\mathrm{P}<0.00001$ ) as compared with the control group. And the NPWT group showed higher proportion of patients with wound coverage than the control group. While no significant difference was found between the two groups in terms of function score and other complications including deep infection rate, amputation and bone nonunion.

Conclusion

Based on the pooled results, we suggested that NPWT could be an alternative choice over traditional gauze dressings in managing the wound of open fracture of lower limbs.

\section{Introduction}

Open fracture, in which the fracture end is exposed to the external environment, still remains a challenging problem for orthopedists due to the concomitant severe injuries of surrounding soft tissues [1]. When an open fracture occurs in the lower limber, especially the tibia, the situation tends to get worse with more serious wound contamination and soft tissue injuries [2]. The management principal of lower limbers open fracture comprises fracture fixation, thorough debridement and soft tissue reconstruction [3,4]. Stable fracture fixation can be achieved through implanted plates in the early stage, while the soft tissue reconstruction particularly in Gustilo $₫$ open tibia fracture usually require the flap transplantation to cover the wound $[5,6]$. The soft tissue reconstruction is critical for the function and shape recovery, and improper treatment will result in serious complications, including morbidity, infection and even amputations [7].

Despite the progress of flap transplantation and patient nursing, wound infection and deep infection are still a headache bothering orthopedists [7]. In complex wound treatment, the aseptic dressing is often applied as soft tissue coverage to help clean the wound and control wound infection before skin grafting [8, 9]. The use of sterile gauze dressing was a traditional method to cover wound, but this paradigm has changed over the last decades, with negative pressure wound therapy (NPWT) being used more frequently now [10]. NPWT is a novel wound dressing system with continues or intermittent negative pressure applied to the wound area. Since it was introduced 20 years ago, NPWT was firstly applied as an adjuvant therapy for treating complex open fracture, and subsequently many clinical studies have demonstrated its clinical efficacy [11]. Currently, many medicine institutes have used NPWT as a standard treatment for open fracture of lower limbs. The advocators of NPWT argued that the negative pressure system can reduce the tissue oedema, accelerate removing the wound exudate and promote granulation tissue formation, thereby accelerating wound healing and reducing infection rate [9, 12]. However, the use of NPWT was reported to increase the medicine costs due to the equipment use and nursing costs [13]. Therefore, whether these theorical advantages of NPWT could be translated into clinical benefits still remained a controversial topic $[7,12,14]$. Recently, some systematic reviews have been conducted to compare the clinical outcomes of NPWT and traditional gauze dressing. Jun-Ho Kim et al [2] found that NPWT reduced the infection rate, flap necrosis and revision rate. Meanwhile, Marc C. Grant-Freemantle, MCh et al [15] and Xi Liu et al [16] also found that patients receiving NPWT showed lower deep infection rate than patients receiving gauze coverage. However, the inclusion of retrospective studies impaired the evidence level of these published systematic reviews to some extent. In addition, recently there were some published randomized controlled trials (RCTs) suggesting no clinical superiority of NPWT over standard gauze dressings in treating open lower limbs fracture $[3,12,17]$.

Therefore, whether NPWT could reduce the infection rate of open lower limbs fracture and benefit patients more when compared with the traditional gauze dressing still remains to be further clarified. And it is necessary to update such a systematic review with only high-quality RCTs included, which will theoretically provide us with higher-level evidence to compare the efficacy of the two treatments.

Herein, we carried out this updated meta-analysis with high-quality RCTs included to comprehensively compare the clinical efficacy of NPWT and standard gauze dressings.

\section{Materials And Methods}

\section{Literature search}

This meta-analysis was conducted according to the Preferred Reporting Items for Systematic Reviews and Meta-Analyses (PRISMA) guidelines [18]. A comprehensive electronic searching of various databases including Web of Science, Medline, PubMed, Clinicaltrial.gov and Cochrane Library was conducted for eligible studies by two independent reviewers (H.Q. and T.L.). The searching strategy was as follows: (Negative pressure wound therapy OR NPWT OR 
Vacuum-assisted closure) AND (Fracture OR Open fracture). There is no limitation on the study design, publication status and publication years when searching databases. The reviewers also screened the reference list of included studies for additionally eligible studies.

\section{Inclusion and Exclusion Criteria}

Only prospective randomized controlled trials (RCTs) directly comparing the clinical outcomes between NPWT and standard gauze dressings for the wound management of open fracture of lower limbs were included. Inclusion criteria: (1) RCTs in English (published or unpublished); (2) Studies reporting that all patients suffering from open fracture of lower limbs were managed with NPWT (any systems) or traditional gauze dressings; (3) Studies reporting the following clinical outcomes: Overall infection rate, deep infection rate, acute wound infection rate, time for wound healing, disability rating index (DRI), positive rate for culturing, length of hospital stay and complications. et. al; (4) Studies available for full-text. Exclusion criteria: (1) Non-RCTs; (2) Only one study should be included for repeated studies involving the same patients; (3) Studies only reporting the cost-effectiveness analysis of NPWT; (4) Studies including patients treated with other management; (5) Studies reporting more than $20 \%$ patients were lost to follow-up.

\section{Study selection}

A total of 967 records were identified through originally searching in various databases and screening the reference lists. After 296 duplicates were removed by EndNote ${ }^{\text {TM }}$ automatically and manually, the title and abstract of the remaining 671 records were screened for eligibility. Two reviewers conducted full-text review in 23 studies for potentially eligible studies, and 13 studies were excluded ( 3 systematic review, 2 content irrelevant, 8 non-RCTs). Finally, 10 RCTs were included in the present meta-analysis. Any disagreements were settled by a third author (Y.H.). The flow diagram of study selection was shown in Figure. 1.

\section{Study Quality Assessment}

Two reviewers assessed the quality of the included studies independently according to the Cochrane Collaboration's tool for assessing risk of bias in RCTs [19]. The study quality assessment comprised 7 items including random sequence generation, allocation concealment, blinding of participants and personnel, incomplete outcome data, selective reporting, and other bias. All of these items were rated as high risk, low risk and unclear risk. Any disagreement about the study quality assessment was addressed by discussion and consultation.

\section{Data Extraction}

Data extraction was performed by two independent reviewers. All relevant data in included RCTs was collected in a prepared form, and data presented as mean and $95 \%$ confidence interval $(\mathrm{Cl})$ was transformed to the form of mean \pm SD according to the Cochrane Handbook [20]. The baseline data comprised of the first author, study design, publication years, country, number of patients, mean age, sex and duration of following up. The clinical characteristics of included patients contained Gustilo and Anderson classification, preoperative diagnosis of diabetics, smoking and method of wound closure. The data of clinical outcomes included overall infection rate, deep infection rate, acute wound infection rate, time for wound healing, DRI, the quality-of-life EuroQol-5 Dimensions (EQ-5D), positive rate for culturing, length of hospital stay and complications. A discussion was conducted to reach agreement if any disagreements between reviewers occurred.

\section{Statistical Analysis}

Data analysis was completed using Review Manager (RevMan, Version 5.4, USA). Dichotomous data was analyzed and presented with Odd Ratio (ORs) and

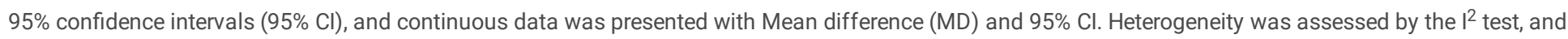
significant heterogeneity existed if $P<0.10$ and $\mathrm{I}^{2}>50 \%$. If the heterogeneity was significant, a random-effect model was applied, otherwise, a fixed-effect model was used. A $P$ value $<0.05$ was considered as statistically significant.

\section{Results}

\section{Characteristics of included RCTs}

Eventually, a total of 10 RCTs involving 2780 patients, comprising of 1394 patients managed with NPWT and 1386 patients managed with traditional gauze dressings, were included in this meta-analysis [3, 7, 9, 12, 17, 21-25]. The baseline data of included RCTs was presented in Table 1. Each included study was prospective randomized controlled trial, and the publication years ranged from 2009 to 2021. Most studies were completed in Asia (seven studies), two in Europe and another one in America. The follow-up period ranged from 1 to 36 months and the mean age ranged from 31.9 to 49.8 years. Overall, there was no significant difference in patient number, mean age, BMI, follow-up period and sex proportions between the two groups. The clinical characters of included RCTs were summarized in Table 2. All patients were Type II or III fracture according to the Gustilo and Anderson classification. Similarly, there were no significant difference between the NPWT and control groups in terms of fracture type, diagnosis of diabetics, smoking and method of wound closure. Figure. 2 showed the quality evaluation of included RCTs. As a whole, the risk of bias of included studies was minor, but three studies were rated to high risk in blinding of participants and personnel $[3,12,17]$. Most studies were judged as unclear risk because the authors did not state the random sequence generation, allocation concealment, blinding of outcome assessment and incomplete outcome data clearly. 
Table 1

Baseline data of included studies

\begin{tabular}{|c|c|c|c|c|c|c|c|c|c|c|c|c|c|c|}
\hline \multirow[t]{2}{*}{ Included Studies } & \multirow[t]{2}{*}{ Year } & \multirow[t]{2}{*}{ Design } & \multirow[t]{2}{*}{ Country } & \multicolumn{2}{|c|}{ Patients } & \multicolumn{2}{|c|}{ Fracture } & \multirow{2}{*}{$\begin{array}{l}\text { Follow } \\
\text { up } \\
\text { (Month) }\end{array}$} & \multicolumn{2}{|c|}{ Mean Age } & \multicolumn{2}{|l|}{ BMI } & \multicolumn{2}{|c|}{ Sex (Female/Male) } \\
\hline & & & & NPWT & ST & NPWT & ST & & NPWT & ST & NPWT & ST & NPWT & ST \\
\hline Stannard, JP [7] & 2009 & RCT & USA & 35 & 23 & 37 & 25 & 28 & NA & NA & NA & NA & $9 / 26$ & $10 / 13$ \\
\hline $\begin{array}{l}\text { Jayakumar M } \\
\text { [22] }\end{array}$ & 2013 & RCT & India & 20 & 20 & 20 & 20 & 36 & 32.0 & & NA & NA & NA & NA \\
\hline Sinha K [24] & 2013 & RCT & India & 15 & 15 & 15 & 15 & 12 & 39 & & NA & NA & NA & NA \\
\hline Ketan G [23] & 2013 & RCT & India & 15 & 15 & 15 & 15 & 1.5 & 39 & & NA & NA & $4 / 11$ & $3 / 12$ \\
\hline Ghulam R [21] & 2013 & RCT & Pakistan & 25 & 25 & 25 & 25 & 1.5 & NA & NA & NA & NA & $8 / 17$ & $7 / 18$ \\
\hline Arti H [9] & 2016 & RCT & Iran & 45 & 45 & 45 & 45 & 1 & 31.9 & & NA & NA & $22 / 68$ & \\
\hline Virani SR [25] & 2016 & RCT & India & 43 & 50 & 43 & 50 & 5.75 & 34.8 & 37.4 & NA & NA & $15 / 28$ & $18 / 32$ \\
\hline Costa, ML [12] & 2018 & RCT & England & 220 & 230 & 220 & 230 & 12 & 46.1 & 44.5 & 26.72 & 27.3 & $48 / 178$ & $70 / 164$ \\
\hline Tahir M [3] & 2020 & RCT & Pakistan & 206 & 214 & 206 & 214 & 12 & 37 & 34 & NA & NA & $65 / 141$ & $80 / 134$ \\
\hline Costa ML [17] & 2020 & RCT & England & 770 & 749 & 770 & 749 & 6 & 49.8 & & 26.4 & 26.7 & $320 / 482$ & $281 / 482$ \\
\hline
\end{tabular}

Table 2

Clinical characteristic of included studies

\begin{tabular}{|c|c|c|c|c|c|c|c|c|c|c|c|c|c|c|c|c|}
\hline \multirow{3}{*}{$\begin{array}{l}\text { Included } \\
\text { Studies } \\
\text { NPWT }\end{array}$} & \multicolumn{4}{|c|}{ GA classification } & \multicolumn{2}{|c|}{ Diabetics (n/\%) } & \multicolumn{2}{|c|}{ Smoking (n/\%) } & \multicolumn{8}{|c|}{ Method of wound closure } \\
\hline & \multicolumn{2}{|c|}{ Type II } & \multicolumn{2}{|c|}{ Type III } & \multirow{2}{*}{$\begin{array}{l}\text { NPWT } \\
\text { ST }\end{array}$} & \multirow{2}{*}{$\begin{array}{l}\text { ST } \\
\text { NPWT }\end{array}$} & \multirow{2}{*}{$\begin{array}{l}\text { NPWT } \\
\text { ST }\end{array}$} & \multirow{2}{*}{$\begin{array}{l}\text { ST } \\
\text { NPWT }\end{array}$} & \multicolumn{2}{|c|}{ DPC } & \multicolumn{2}{|c|}{$\begin{array}{l}\text { Flap } \\
\text { (R/F) }\end{array}$} & \multicolumn{2}{|c|}{$\begin{array}{l}\text { Skin } \\
\text { graft }\end{array}$} & \multicolumn{2}{|c|}{ Amputation/clos } \\
\hline & ST & NPWT & ST & NPWT & & & & & ST & NPWT & ST & & & & & \\
\hline $\begin{array}{l}\text { Stannard } \\
\text { JP [7] }\end{array}$ & 2 & 2 & 33 & 23 & $1 / 2.8$ & $0 / 0$ & $18 / 51$ & $7 / 30$ & 21 & 18 & 7 & 3 & 7 & 4 & 2 & 0 \\
\hline $\begin{array}{l}\text { Jayakumar } \\
\text { M [22] }\end{array}$ & NA & NA & NA & NA & NA & NA & NA & NA & NA & NA & NA & NA & NA & NA & NA & NA \\
\hline $\begin{array}{l}\text { Sinha K } \\
\text { [24] }\end{array}$ & 4 & & 26 & & NA & NA & NA & NA & NA & NA & NA & NA & NA & NA & NA & NA \\
\hline $\begin{array}{l}\text { Ketan G } \\
{[23]}\end{array}$ & NA & NA & NA & NA & NA & NA & NA & NA & NA & NA & NA & NA & NA & NA & NA & NA \\
\hline $\begin{array}{l}\text { Ghulam R } \\
\text { [21] }\end{array}$ & NA & NA & NA & NA & NA & NA & NA & NA & NA & NA & NA & NA & NA & NA & NA & NA \\
\hline Arti H [9] & NA & NA & NA & NA & NA & NA & NA & NA & NA & NA & NA & NA & NA & NA & NA & NA \\
\hline $\begin{array}{l}\text { Virani SR } \\
\text { [25] }\end{array}$ & 5 & 8 & 38 & 42 & $3 / 6.9$ & $5 / 10$ & $11 / 25.5$ & $14 / 28$ & 34 & 40 & 1 & 2 & 8 & 8 & 0 & 0 \\
\hline $\begin{array}{l}\text { Costa ML } \\
\text { [12] }\end{array}$ & 34 & 30 & 192 & 204 & $14 / 6.2$ & $13 / 5.6$ & $70 / 31.0$ & $79 / 33.8$ & NA & NA & NA & NA & NA & NA & NA & NA \\
\hline Tahir M [3] & 17 & 21 & 189 & 193 & $25 / 12.1$ & $27 / 12.6$ & $77 / 37.4$ & $81 / 37.9$ & 169 & 172 & 15 & 22 & 19 & 23 & 0 & 0 \\
\hline $\begin{array}{l}\text { Costa ML } \\
\text { [17] }\end{array}$ & NA & NA & NA & NA & $63 / 8.1$ & $85 / 11.3$ & $218 / 28.6$ & $216 / 29.2$ & NA & NA & NA & NA & NA & NA & NA & NA \\
\hline
\end{tabular}

NPWT: Negative pressure wound therapy, ST: Standard treatment, GA classification: Gustilo and Anderson classification, DPC: Delayed primary closure, R/F: Rotational/Free, NA: Not available data,

\section{Meta-analysis}

\section{Anti-infection function evaluation of the two dressings}

For accurate comparison of infection rate between the two groups, we conducted data analysis in terms of overall infection rate, deep infection rate and acute wound infection rate. Totally, 8 RCTs $[3,7,9,12,17,22,23,25]$ involving 2414 patients reported the data of overall infection rate. There was no significant heterogeneity $\left(P=0.06, \mathrm{I}^{2}=48 \%\right)$ detected, and a fixed-effect model was applied for data analysis. The pooled results showed that NPWT reduced the overall infection rate significantly ( $\mathrm{MD}=0.70,95 \% \mathrm{Cl}: 0.54-0.90, P=0.005)$ (Figure. 3a). However, with respect to rate of deep infection, data was available in $6 \mathrm{RCTs}$ comprising 2344 patients $[3,7,9,12,17,25]$. As illustrated in Figure. $3 \mathrm{~b}$, a fixed-effect model was applied for analysis due to the absence of significant heterogeneity $\left(P=0.45, I^{2}=0 \%\right)$, and no significant difference was detected between the two groups $(M D=0.76,95 \% C l: 0.58-1.00, P=0.05)$. Regarding the rate of acute wound infection, 5 RCTs containing 315 patients were included for meta-analysis [7, 9, 22, 23, 25]. Data analysis was performed with a fixed- 
effect model because the heterogeneity was not significant $\left(P=0.29,1^{2}=20 \%\right)$, and the pooled results suggested that the rate of acute wound infection in the NPWT group was significantly reduced (MD $=0.35,95 \% \mathrm{Cl}: 0.16-0.77, P=0.009)$ (Figure. $3 \mathrm{c}$ ). The positive rate for culturing was provided in 3 studies ( 185 patients) $[7,24,25]$. As shown in Figure. 3d, without significant heterogeneity $\left(P=0.67,1^{2}=0 \%\right)$, we conducted the data analysis using a fixed-effect model. The merged result showed that NPWT was effective in reducing the positive rate for culturing (MD $=0.19,95 \% \mathrm{Cl}: 0.08-0.45, P=0.0001)$ compared with traditional gauze dressings. Likewise, we collected data about the rate of clinical infection from positive culturing in 2 RCTs [7, 25]. After merging with a fixedeffect model, no significant difference was identified between the two groups ( $\mathrm{MD}=1.21,95 \% \mathrm{Cl}$ : $0.29-5.06, P=0.80)(\mathrm{Figure}$. 3e).

\section{Efficacy evaluation of promoting wound healing}

Time for wound ready for closure

Regarding the time for wound ready for closure, data from 152 patients in 2 RCTs was available for data analysis [7, 9]. As presented in Figure. 4a, because no significant heterogeneity was found $\left(P=0.42, I^{2}=0 \%\right)$, a fixed-effect model was utilized to finish the meta-analysis, demonstrating that NPWT significantly shortening the time for wound ready for closure (MD $=-1.19,95 \% \mathrm{Cl}:-2.03-0.35, P=0.006)$.

Time for the wound coverage

Regarding the Time for the wound coverage, data was provided in 2 RCTs involving 70 patients [22, 23]. Because of the absence of significant heterogeneity $\left(P=0.92, I^{2}=0 \%\right)$, we used a fixed-effect model to perform the data synthesis and detected that more wound coverage was completed within 3 weeks in the NPWT group (MD = 24.00, 95\% Cl: 6.82-84.46, P< 0.00001), as depicted in Figure. 4b. However, more wound coverage was completed in the ST group beyond 3 weeks ( $\mathrm{MD}=0.04,95 \% \mathrm{Cl}: 0.01-0.15, \mathrm{P}<0.00001)$ (Figure. $4 \mathrm{c}$ ). In summary, NPWT shortened the time for the wound coverage.

Time for wound complete healing

4 RCTs with 475 patients described the information of time for wound complete healing [12, 21-23]. Data analysis was conducted utilizing a random-effect model on account of significant heterogeneity $\left(P<0.0001, \mathrm{I}^{2}=91 \%\right)$. As presented in Figure. $4 \mathrm{~d}$, even though more patients in the NPWT group reported that the wound completely healed within 6 weeks, the difference between the two groups was not statically significant (MD $=7.48,95 \% \mathrm{Cl}: 0.59-94.69, P=0.12)$. Likewise, we found no significant difference between NPWT and ST with respect to wound complete healing beyond 6 weeks (MD $=0.13,95 \%$ Cl: $0.01-1.69, P$ $=0.12$ ) (Figure. 4e). To sum up, NPWT made no significant effect on the time for wound complete healing.

\section{Efficacy evaluation of function restoration}

DRI

DRI information was available in 2 RCTs with over 1200 patients at different time point $[12,17]$. We performed subgroup analysis at postoperative 3 and 6 months. Similarly, the data of DRI was not heterogeneous at postoperative 3 months $\left(P=0.48, I^{2}=0 \%\right)$ and 6 months $\left(P=0.32, I^{2}=0 \%\right)$, a fixed-effect model was applied to merge results. And the pooled results suggested that NPWT could improve the DRI at postoperative 3 months (MD $=0.49,95 \%$ Cl: $0.23-0.76$, $\mathrm{P}=0.0003)$ and 6 months $(\mathrm{MD}=0.41,95 \% \mathrm{Cl}: 0.10-0.72, \mathrm{P}=0.01)$. Overall, there was a significant difference between the two groups regarding to $\mathrm{DRI}(\mathrm{MD}=$ $0.46,95 \% \mathrm{Cl}: 0.25-0.66, \mathrm{P}<0.0001$ ) (Figure. $5 \mathrm{a}$ ).

EQ-5D

EQ-5D was reported in 2 RCTs (1296 patients) $[12,17]$. As shown in Figure. 5b, because no significant heterogeneity between the two groups was detected $(P=$ $0.77,1^{2}=0 \%$, data analysis was conducted using a fixed-effect model, and the difference between NPWT and ST was not significant (MD $=-0.00,95 \%$ Cl: $-0.00-0.00, P=0.99)$.

Length of hospital stay

In terms of length of hospital stay, 2 RCTs were included for data analysis [22, 23]. For length of hospital stay < 1 month, as shown in Figure. $5 \mathrm{c}$, the heterogeneity was not significant $\left(P=0.92, I^{2}=0 \%\right)$ and a fixed-effect model was used for data analysis, showing that more patients in the NPWT group discharged within 1 month postoperatively $(\mathrm{OR}=24.00,95 \% \mathrm{Cl}: 6.82-84.46, \mathrm{P}<0.00001)$. On the contrary, more patients in the ST group discharged beyond 1 month postoperatively $(\mathrm{OR}=0.04,95 \% \mathrm{Cl}$ : $0.01-0.15, \mathrm{P}<0.00001)$ (Figure. $5 \mathrm{~d})$. In short, NPWT shortened the length of hospital stay significantly.

\section{Complications}

Due to the data availability, we selected 2 complications containing amputation and bone nonunion for meta-analysis, which were reported in 2 RCTs at least. We merged each complication with a fixed-effect model because the heterogeneity was not significant. The pooled results were summarized in Figure. 6 . The difference between NPWT and ST regarding each complication was not statistically significant.

\section{Discussion}

Open fracture of lower extremities, especially for Gustilo type $₫$ tibia fracture, is a challenging problem for orthopedists, which is usually companied with severe soft tissue injuries and wound contamination [12]. The wound management is a critical part in the treatment of open fracture of lower extremity. Different from standard gauze dressings, the NPWT is a special dressing with negative pressure exerted on the wound area, and the negative pressure on the wound was reported to promote the healing of various wound [7]. Currently, NPWT has been a conventionally used dressing for managing the wound of open 
fracture of lower extremities in some medicine institutions. However, recent publications including systematic reviews and RCTs could not reach an agreement with respect to the clinical superiority of NPWT over traditional dressings $[2,3,15,17]$. In this study, we updated such a meta-analysis only including RCTs to comprehensively compare the clinical efficacy of traditional gauze dressings and NPWT. Postoperative infection is a severe complication for open fracture of lower extremities, the incidence of which was significantly higher than that of closed fracture [26, 27]. Therefore, the postoperative infection rate was a prominent indicator for evaluating the treatment choice of open fracture. After pooling and analysing the available data, we found that patients receiving NPWT showed lower total infection rate and acute wound infection rate than patients receiving traditional gauze dressings, which was consistent with the previous systematic reviews $[2,15]$. The two published reviews suggested that the reduced acute wound infection rate may be due to the promoting-healing effect of the negative pressure on the wound area, since there were sufficient evidence suggesting that NPWT could promote wound healing through reducing oedema, increasing tissue granulation and angiogenesis $[16,28]$. We also found that the proportion of patients with suture conditions in the NPWT group was higher within three weeks, and the proportion of patients with wound healing in the NPWT group was higher than that in the control group within six weeks. This founding suggested that the use of NPWT could accelerate wound healing of open fracture of lower limbs. In addition, we also found that the positive rate of bacterial culture in the NPWT group was lower than the control group, but no significant difference was detected in the clinical infection rate of culturepositive patients in both groups. This founding suggested that the use of NPWT had a bacterial-removal effect, which was consistent with previous experimental researches and proved the clinical effect of NPWT on reducing the acute wound infection rate to a certain degree [14, 29].

However, it was worth noting that we found no significant difference between the two groups with respect to the deep infection rate in our study. For open fracture of lower extremities, deep site infection is a more serious and complex complication than the acute wound infection. And whether the application of NPWT could reduce the deep infection rate still remained a controversy. Stannard JP et a/ reported a lower deep infection rate in the NPWT group (5.4\%) than the control group (20\%) receiving traditional gauze dressings [7]. However, this RCTs only included 59 patients and the small ample size limited its evidence level. Meanwhile, some large multicenter RCTs recently reported no significant difference between the NPWT and control groups regarding the deep infection rate, which was consistent with the pooled results in this study $[3,17]$. In fact, the occurrence of deep infection is associated with many factors, such as fracture type and antibiotic intervention. Dedmond et al suggested that the deep infection rate of open fracture of lower extremities was different according to the fracture type, with a $12.5 \%$ infection rate for type IIIA, and a 50\% rate for type IIIC [10]. In addition, Hannigan GD et al reported that patients' conditions including smoking history, transfusion time and diabetes were closely associated with the incidence of deep infection of open fracture [30]. Therefore, the choice of wound dressings is not the critical determinant for reducing the deep infection incidence of open fracture of lower limbs. As for other complications, we found no significant difference between the two groups in term of amputations and bone nonunion rate, the occurrence of which was also multifactorial and not determined by the choice of dressings [2]. There were two RCTs evaluating the function restoration of lower limbs after receiving NPWT or traditional dressings therapies. We found that patients in the NPWT group showed higher DRI score than the control group at 3 months (mean difference: $0.49,95 \%$ Cl: $0.23-0.76$ ) and 6 months (mean difference: $0.41,95 \% \mathrm{Cl}$ : $0.10-0.72$ ). Although a statistically significant difference was detected between the two groups in the DRI score, this subtle difference made no clinical significance. Meanwhile, we found no significant difference between the two groups in EQ-5D score. The pooled results of function score suggested no superiority of NPWT over traditional gauze dressings in terms of lower extremity function recovery. However, we found that the proportion of patients hospitalized less than 1 month in the NPWT was significantly higher than the control group. The reduced hospitalization of the NPWT group may be contributed to the promoting wound-healing and bacterial clearance effect of NPWT. Overall, based on the pooled results of our analysis, we suggested that NPWT could be an alternative choice over traditional gauze dressings in managing the wound of open fracture of lower limbs, since we found that NPWT could reduce the acute wound infection rate and promote wound healing, thereby reducing the hospitalization of patients.

\section{Study strengths and limitations}

This updated meta-analysis included 10 RCTs, with a total of 2780 patients included. The inclusion of RCTs and the large sample size improved the evidence level of this study. To our best knowledge, this is the first meta-analysis including all the RCTs to compare the clinical efficacy of NPWT and traditional gauze dressings on treating open fracture of lower limbs. Nevertheless, some limitations should be notified when generalizing the conclusion of this study. Firstly, due to the data availability, we cannot perform a subgroup analysis to compare the clinical effects of the two dressings on different types of open fracture wounds of lower limbs, which could result in the production of heterogeneity. Secondly, the longest follow-up period of these included RCTs was 1 year and the lack of long-term follow-up data impaired the evidence level in this study. Finally, the language bias should be notified since we only included studies published in English.

\section{Conclusion}

The present study found that the application of NPWT for treating open fracture of lower limbs could reduce the acute wound infection rate and total infection rate, promote wound healing and shorten hospital stay, as compared with traditional gauze dressings. Meanwhile, no significant difference was found between the two groups in term of deep infection rate, DRI and EQ-5D score. Herein, we suggested that NPWT could be an alternative choice over traditional gauze dressings for managing the wound of open fracture of lower limbs.

\section{Declarations}

\section{Acknowledgements:}

None

\section{Conflict of Interest:}

The authors report no conflict of interest. 


\section{References}

1. Louie KW. Management of open fractures of the lower limb. BMJ (Clinical research ed.). 2009;339:b5092. doi:10.1136/bmj.b5092.

2. Kim JH, Lee DH. Negative pressure wound therapy vs. conventional management in open tibia fractures: Systematic review and meta-analysis. Injury. 2019;50:1764-72. doi:10.1016/j.injury.2019.04.018.

3. Tahir M, Chaudhry EA, Zimri FK, Ahmed N, Shaikh SA, Khan S, Choudry UK, Aziz A, Jamali AR Negative pressure wound therapy versus conventional dressing for open fractures in lower extremity trauma. The bone \& joint journal 2020, 102-b, 912-917, doi:10.1302/0301-620x.102b7.bjj-2019-1462.r1.

4. Godina M. Early microsurgical reconstruction of complex trauma of the extremities. Plast Reconstr Surg. 1986;78:285-92. doi:10.1097/00006534198609000-00001.

5. Schlatterer DR, Hirschfeld AG, Webb LX. Negative pressure wound therapy in grade IIIB tibial fractures: fewer infections and fewer flap procedures? Clin Orthop Relat Res. 2015;473:1802-11. doi:10.1007/s11999-015-4140-1.

6. Matos MA, Lima LG, de Oliveira LA. Predisposing factors for early infection in patients with open fractures and proposal for a risk score. Journal of orthopaedics traumatology: official journal of the Italian Society of Orthopaedics Traumatology. 2015;16:195-201. doi:10.1007/s10195-015-0345-z.

7. Stannard JP, Volgas DA, Stewart R, McGwin G Jr, Alonso JE. Negative pressure wound therapy after severe open fractures: a prospective randomized study. J Orthop Trauma. 2009;23:552-7. doi:10.1097/BOT.0b013e3181a2e2b6.

8. Ousey KJ, Atkinson RA, Williamson JB, Lui S. Negative pressure wound therapy (NPWT) for spinal wounds: a systematic review. The spine journal: official journal of the North American Spine Society. 2013;13:1393-405. doi:10.1016/j.spinee.2013.06.040.

9. Arti H, Khorami M, Ebrahimi-Nejad V. Comparison of negative pressure wound therapy (NPWT) \&conventional wound dressings in the open fracture wounds. Pak J Med Sci. 2016;32:65-9. doi:10.12669/pjms.321.8568.

10. Dedmond BT, Kortesis B, Punger K, Simpson J, Argenta J, Kulp B, Morykwas M, Webb LX. The use of negative-pressure wound therapy (NPWT) in the temporary treatment of soft-tissue injuries associated with high-energy open tibial shaft fractures. J Orthop Trauma. 2007;21:11-7. doi:10.1097/ВOT.0b013e31802cbc54.

11. Yusuf E, Jordan X, Clauss M, Borens $O$, Mäder M, Trampuz A. High bacterial load in negative pressure wound therapy (NPWT) foams used in the treatment of chronic wounds. Wound repair regeneration: official publication of the Wound Healing Society [and] the European Tissue Repair Society. 2013;21:67781. doi:10.1111/wrr.12088.

12. Costa ML, Achten J, Bruce J, Tutton E, Petrou S, Lamb SE, Parsons NR. Effect of Negative Pressure Wound Therapy vs Standard Wound Management on 12-Month Disability Among Adults With Severe Open Fracture of the Lower Limb: The WOLLF Randomized Clinical Trial. Jama. 2018;319:2280-8. doi:10.1001/jama.2018.6452.

13. Kim JJ, Franczyk M, Gottlieb LJ, Song DH. Cost-effective Alternative for Negative-pressure Wound Therapy. Plast Reconstr Surg Glob Open. $2017 ; 5: e 1211$. doi:10.1097/gox.0000000000001211.

14. Blum ML, Esser M, Richardson M, Paul E, Rosenfeldt FL. Negative pressure wound therapy reduces deep infection rate in open tibial fractures. J Orthop Trauma. 2012;26:499-505. doi:10.1097/BOT.0b013e31824133e3.

15. Grant-Freemantle MC, Ryan É, Flynn J, Moloney SO, Kelly DP, Coveney MA, O’Daly El, Quinlan BJ. J.F. The Effectiveness of Negative Pressure Wound Therapy Versus Conventional Dressing in the Treatment of Open Fractures: A Systematic Review and Meta-Analysis. J Orthop Trauma. 2020;34:223-30. doi:10.1097/bot.0000000000001750.

16. Liu X, Zhang H, Cen S, Huang F. Negative pressure wound therapy versus conventional wound dressings in treatment of open fractures: A systematic review and meta-analysis. International journal of surgery (London England). 2018;53:72-9. doi:10.1016/j.ijsu.2018.02.064.

17. Costa ML, Achten J, Knight R, Bruce J, Dutton SJ, Madan J, Dritsaki M, Parsons N, Fernandez M, Grant R, et al. Effect of Incisional Negative Pressure Wound Therapy vs Standard Wound Dressing on Deep Surgical Site Infection After Surgery for Lower Limb Fractures Associated With Major Trauma: The WHIST Randomized Clinical Trial. Jama. 2020;323:519-26. doi:10.1001/jama.2020.0059.

18. Moher D, Liberati A, Tetzlaff J, Altman DG. Preferred reporting items for systematic reviews and meta-analyses: the PRISMA statement. PLoS Med. 2009;6:e1000097. doi:10.1371/journal.pmed.1000097.

19. Higgins JP, Altman DG, Gøtzsche PC, Jüni P, Moher D, Oxman AD, Savovic J, Schulz KF, Weeks L, Sterne JA. The Cochrane Collaboration's tool for assessing risk of bias in randomised trials. BMJ (Clinical research ed.). 2011;343:d5928. doi:10.1136/bmj.d5928.

20. Hozo SP, Djulbegovic B, Hozo I. Estimating the mean and variance from the median, range, and the size of a sample. BMC Med Res Methodol. 2005;5:13. doi:10.1186/1471-2288-5-13.

21. Ghulam Rasool MUA, Iqbal M, Khwaja Z. Vacuum assited wound closure and normal saline dressing in treatment of Gustilo type II, type IIla and IIIb open fracture of tibia. Rawal Med J. 2013;38:382-4.

22. Jayakumar M. A.P. A comparative study between primary vacuum assisted closure and conventional sterile dressing in treatment of soft tissue injuries associated with severe open fractures of both bones leg. Kerala J Orthop. 2013;26:8-12.

23. Ketan Gupta AM, Patil A. Comparison of Vacuum Assisted Closure Therapy with Standard Wound Therapy for Open Musculoskeletal Injuries. Int J Recent Trends Sci Technol. 2013;9:168-70.

24. Sinha K, Chauhan VD, Maheshwari R, Chauhan N, Rajan M, Agrawal A Vacuum Assisted Closure Therapy versus Standard Wound Therapy for Open Musculoskeletal Injuries. Advances in orthopedics 2013, 2013, 245940-245940, doi:10.1155/2013/245940.

25. Virani SR, Dahapute AA, Bava SS, Muni SR. Impact of negative pressure wound therapy on open diaphyseal tibial fractures: A prospective randomized trial. J Clin Orthop Trauma. 2016;7:256-9. doi:10.1016/j.jcot.2016.05.007. 
26. Jacob E, Erpelding JM, Murphy KP. A retrospective analysis of open fractures sustained by U.S. military personnel during Operation Just Cause. Mil Med. 1992;157:552-6.

27. Yokoyama K, Itoman M, Shindo M, Kai H. Contributing factors influencing type III open tibial fractures. The Journal of trauma. 1995;38:788-93. doi:10.1097/00005373-199505000-00019.

28. Rinker B, Amspacher JC, Wilson PC, Vasconez HC. Subatmospheric pressure dressing as a bridge to free tissue transfer in the treatment of open tibia fractures. Plast Reconstr Surg. 2008;121:1664-73. doi:10.1097/PRS.0b013e31816a8d9d.

29. Liu D, Zhang L, Li T, Wang G, Du H, Hou H, Han L, Tang P. Negative-pressure wound therapy enhances local inflammatory responses in acute infected softtissue wound. Cell Biochem Biophys. 2014;70:539-47. doi:10.1007/s12013-014-9953-0.

30. Hannigan GD, Pulos N, Grice EA, Mehta S. Current Concepts and Ongoing Research in the Prevention and Treatment of Open Fracture Infections. Adv Wound Care (New Rochelle). 2015;4:59-74. doi:10.1089/wound.2014.0531.

\section{Figures}

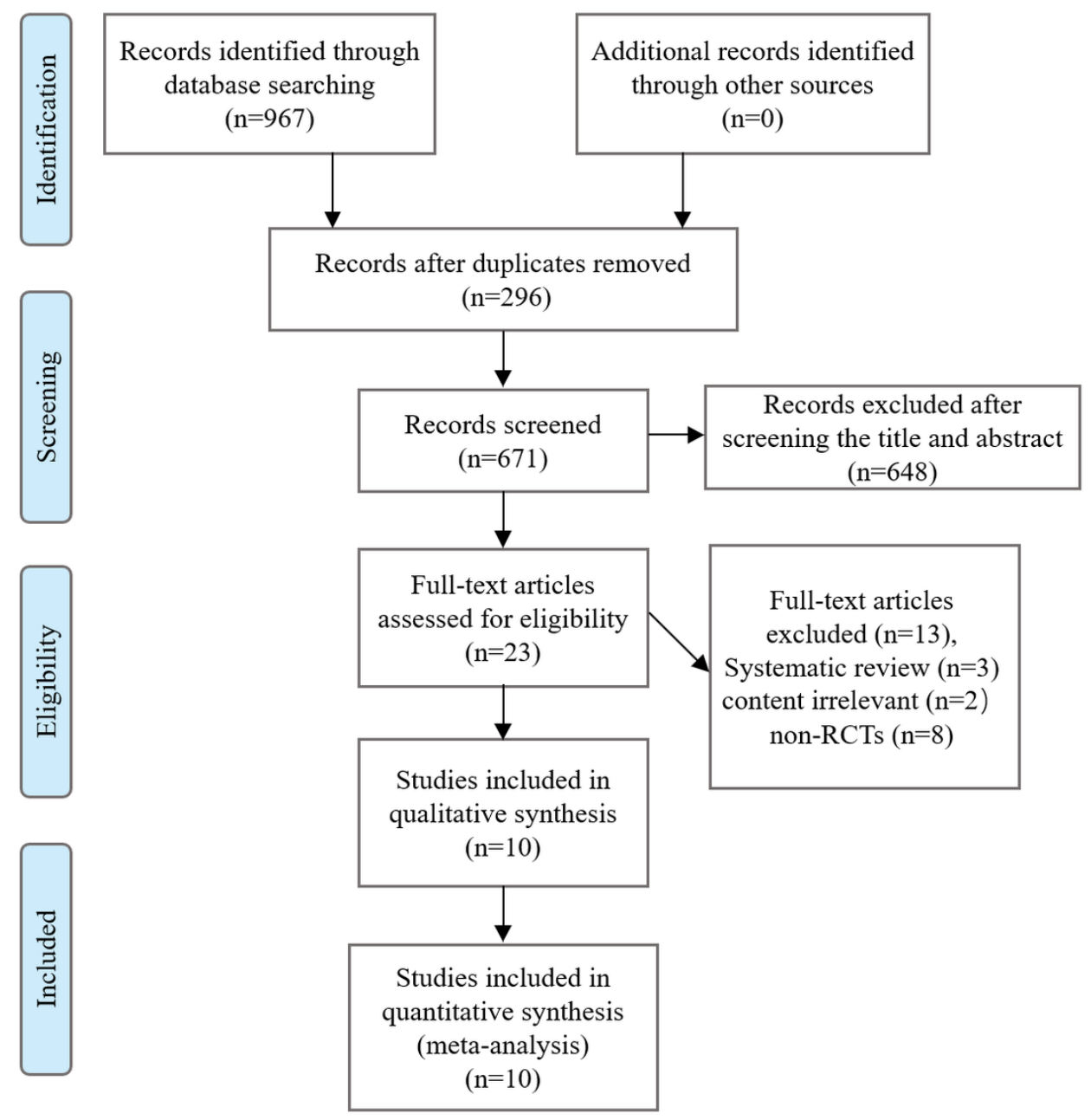

Figure 1

Flow diagram of study searching according to the PRISMA (Preferred Reporting Items for Systemic Meta-Analyses) guideline. 
(a)

(b)
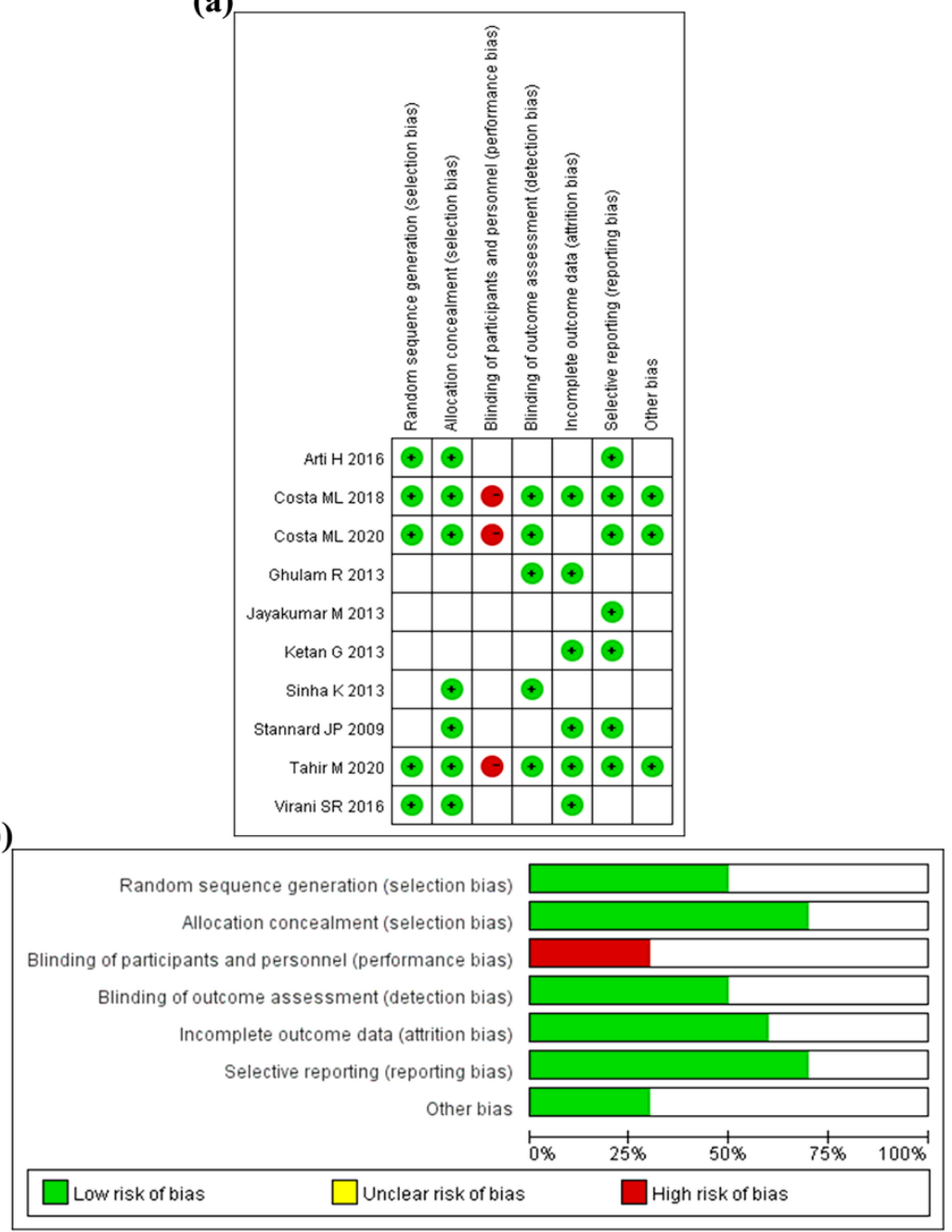

\section{Figure 2}

Quality evaluation of included RCTs utilizing the Risk of bias tool of the Cochrane Library for RCTs. (a) Risk of bias graph for each included study, (b) Risk of bias summary presented as percentages across all included studies. 


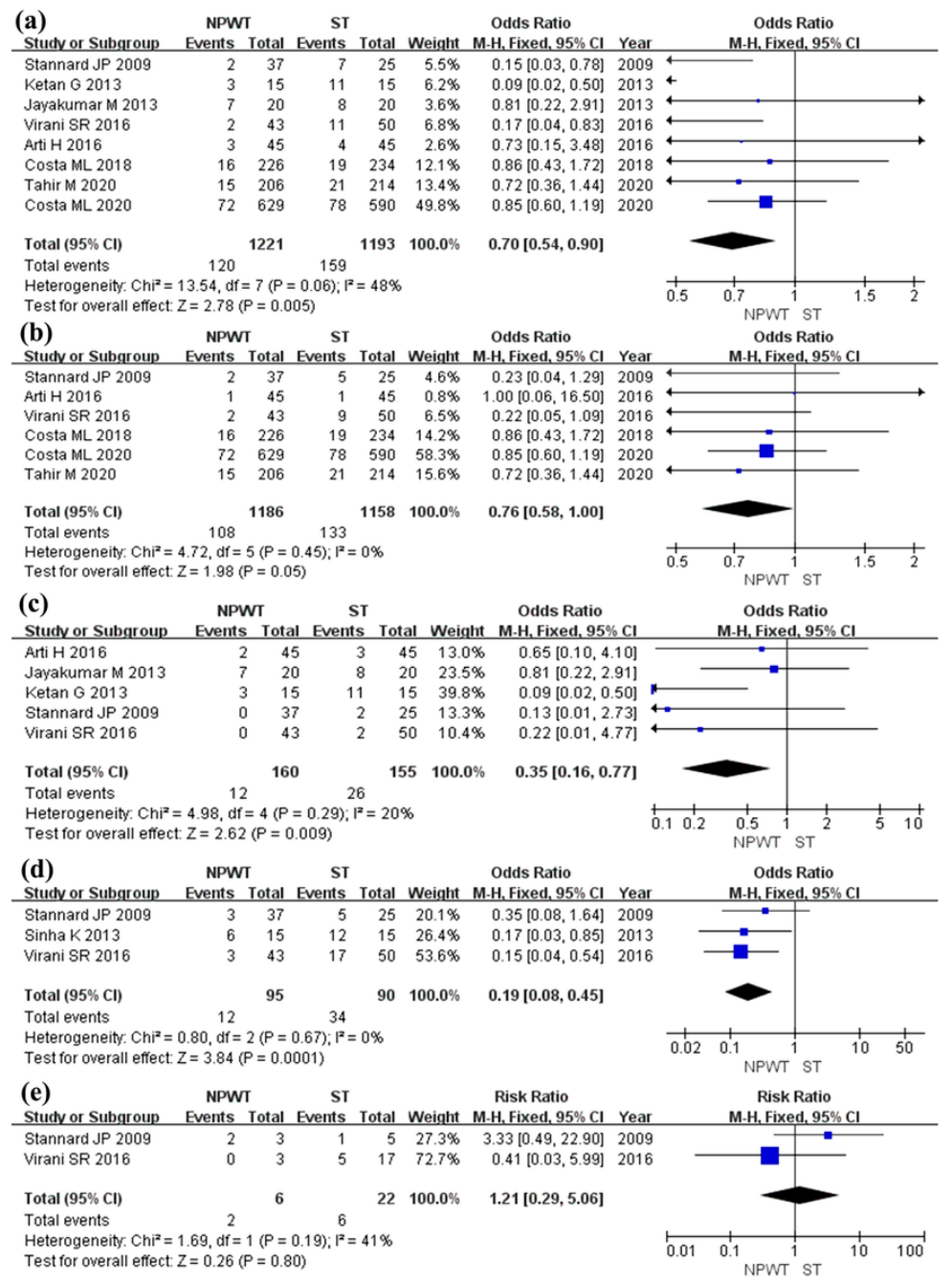

\section{Figure 3}

Forest plot demonstrating the anti-infection function. (a) the rate of overall infection, (b) the rate of deep infection, (c) the rate of acute wound infection, (d) the positive rate for culturing, and (e)the rate of clinical infection from positive culturing. 
(a)

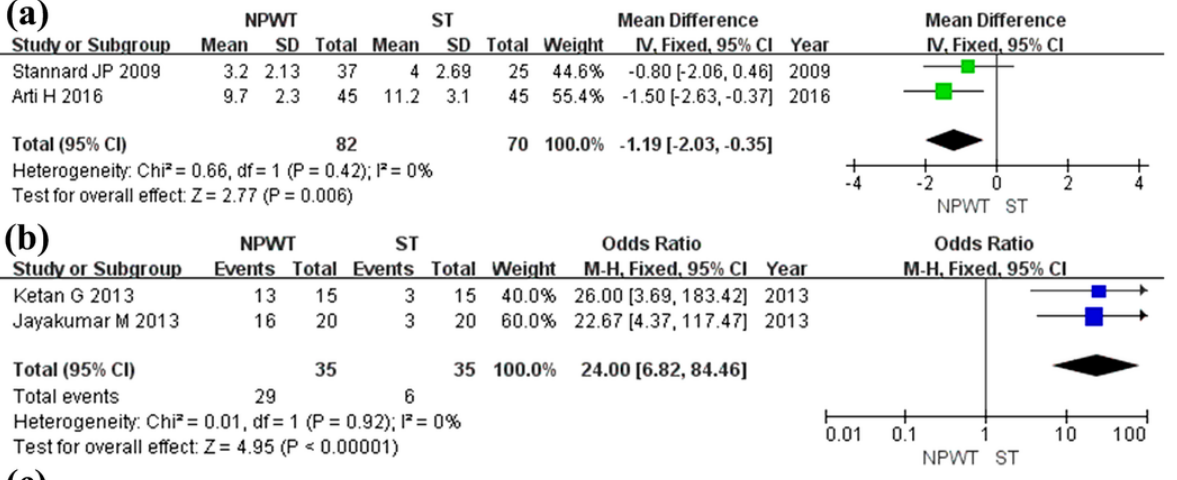

Test for overall effect: $Z=4.95$ ( $P<0.00001)$

\section{(c)}

$\begin{array}{lll}\text { NPWT } & \text { ST } & \text { Odds Ratio }\end{array}$

Study or Subgroup Events Total Events Total Weight M-H, Fixed, 95\% Cl Year

$\begin{array}{llllllll}\text { Ketan G } 2013 & 2 & 15 & 12 & 15 & 43.3 \% & 0.04[0.01,0.27] & 2013\end{array}$

$\begin{array}{llllllll}\text { Jayakumar M } 2013 & 4 & 20 & 17 & 20 & 56.7 \% & 0.04[0.01,0.23] & 2013\end{array}$

$\begin{array}{lllll}\text { Total }(95 \% \mathrm{Cl}) & 35 & 35 & \mathbf{1 0 0 . 0 \%} & 0.04[0.01,0.15]\end{array}$

Total events 629

Heterogeneity: $\mathrm{Chi}^{2}=0.01, \mathrm{df}=1(\mathrm{P}=0.92) ; \mathrm{I}^{2}=0$ \%

Test for overall effect: $Z=4.95$ ( $P<0.00001)$

\section{(d)}

$$
\text { NPWT ST }
$$

ST Odds Ratio

Odds Ratio

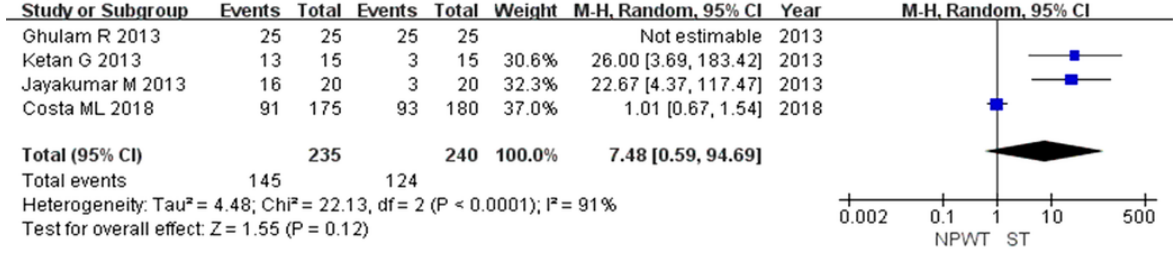

\section{(e)}

ST Odds Ratio

Odds Ratio

Study or Subgroup Events Total Events Total Weight M.H. Random. 95\% Cl Year

Ketan $\& 2013$

Jayakumar M 2013

Ghulam R 2013

Costa ML 2018

$\begin{array}{rrrrr}2 & 15 & 12 & 15 & 30.6 \%\end{array}$

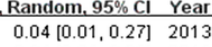

M. Odds Ratio

Total $(95 \% \mathrm{Cl})$

Total events

$\begin{array}{rrrrrrr}4 & 20 & 17 & 20 & 32.3 \% & 0.04[0.01,0.23] & 2013 \\ 0 & 25 & 0 & 25 & & \text { Not estimable } & 2013 \\ 84 & 175 & 87 & 180 & 37.0 \% & 0.99[0.65,1.50] & 2018\end{array}$

Hetergeneity: $\mathrm{Tau}^{2}=4.48 ; \mathrm{Chi}^{2}=22.13, \mathrm{df}=2(\mathrm{P}<0.0001) ; \mathrm{I}^{2}=91 \%$

$0.13[0.01,1.69]$

$235 \quad 240 \quad 100.0 \%$

116

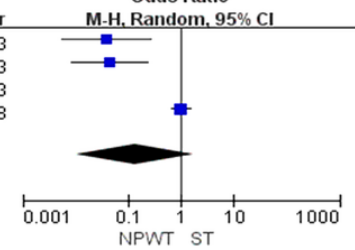

\section{Figure 4}

Forest plot demonstrating the efficacy evaluation of promoting wound healing. (a) time for wound ready for closure, (b) the rate of the time for the wound coverage $<3$ weeks, (c) time for the wound coverage $>3$ weeks, (d) time for wound complete healing $<6$ weeks, (e) time for wound complete healing $>6$ weeks. 


\section{(a)}

NPWT

ST

Mean Difference

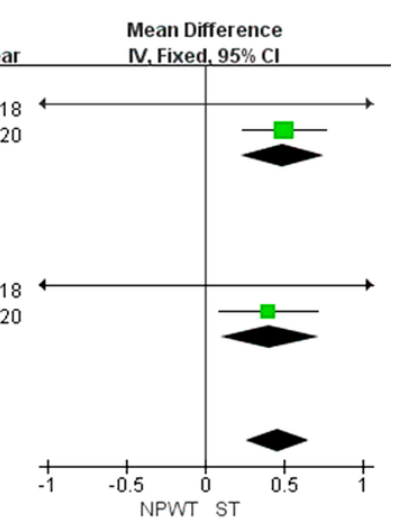

\begin{tabular}{lll} 
Study or Subgroup Mean SD Total Mean SD Total Weight IV. Fixed, 95\% Cl Year & IV. Fixed, $95 \% \mathrm{Cl}$ \\
\hline 2.1.1 Disability Rating Index-3M & &
\end{tabular}

Costa ML 2018

$\begin{array}{llllllllll}64.3 & 22.3 & 166 & 65.6 & 20.1 & 188 & 0.2 \% & -1.30[-5.75,3.15] & 2018\end{array}$

Subtotal $(95 \% \mathrm{Cl})$

$\begin{array}{llll}51.6 & 2.05 \quad 507 \\ & & 0\end{array}$

673

Te ${ }^{2}=0.63, \mathrm{df}=1(P=0.43) ;\left.\right|^{2}=0 \%$

Test for overall effect: $Z=3.60(P=0.0003)$

2.1.2 Disability Rating Index-6M

$\begin{array}{lrllll}\text { Costa ML 2018 } & 53.2 & 23.8 & 166 & 50.3 & 24.1 \\ \text { Costa ML 2020 } & 40.6 & 2.25 & 469 & 40.2 & 2.55 \\ \text { Subtotal (95\% Cl) } & & & \mathbf{6 3 5} & & \end{array}$

40.22 .55

$175-0.2 \%-2.90[-2.19,7.99) 2018$

$\begin{array}{llll}432 & 42.1 \% & 0.40[0.08,0.72] & 2020\end{array}$

$607 \quad 42.2 \% \quad 0.41[0.10,0.72]$

Test for overall effect: $Z=2.55(P=0.01)$

Total $(95 \% \mathrm{Cl}) \quad 1308$

$1251100.0 \% \quad 0.46[0.25,0.66]$

Heterogeneity: $\mathrm{Chi}^{2}=1.71, \mathrm{df}=3(\mathrm{P}=0.63) ; \mathrm{I}^{2}=0 \%$

Test for overall effect: $Z=4.39(P<0.0001)$

Test for subaroun differences: $\mathrm{Chi}^{2}=0.16 . \mathrm{df}=1(\mathrm{P}=0.69) . \mathrm{I}^{2}=0 \%$

\section{(b)}

Study or Subaroup MPWT $\quad$ ST $\quad$ Mean Difference

Mean Difference Mean Difference

\begin{tabular}{llllllllll}
\hline Costa ML 2018 & 0.55 & 0.33 & 172 & 0.56 & 0.32 & 192 & $0.2 \%$ & $-0.01[-0.08,0.06]$ & 2018
\end{tabular}

$\begin{array}{llllllllll}\text { Costa ML 2020 } & 0.58 & 0.025 & 486 & 0.58 & 0.025 & 446 & 99.8 \% & 0.00[-0.00,0.00] & 2020\end{array}$

Total $(95 \% \mathrm{Cl})$

$638 \quad 100.0 \%-0.00[-0.00,0.00]$

Heterogeneity: $\mathrm{Chi}^{2}=0.09, \mathrm{df}=1(\mathrm{P}=0.77) ; \mathrm{I}^{2}=0 \%$

Test for overall effect: $Z=0.01(P=0.99)$

\section{(c)}

NPWT

ST

Odds Ratio IV. Fixed, $95 \% \mathrm{Cl}$

Study or Subgroup Events Total Events Total Weight M-H, Fixed, 95\% Cl Year

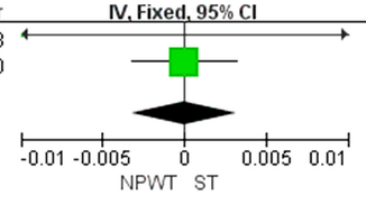

Ketan G 2013

$\begin{array}{ll}13 & 15 \\ 16 & 20\end{array}$

$\begin{array}{lllll}3 & 15 & 40.0 \% & 26.00[3.69,183.42] & 2013\end{array}$

Jayakumar M 2013

Total $(95 \% \mathrm{Cl})$

Total events

35

$35 \quad 100.0 \% \quad 24.00[6.82,84.46]$

$29 \quad 6$

Test for overall effect: $Z=4.95$ ( $P<0.00001)$

\section{(d)}

NPWT

ST

Odds Ratio

Odds Ratio

Study or Subgroup Events Total Events Total Weight M-H, Fixed, 95\% Cl Year

Jayakumar M 2013

4 Total

$\begin{array}{lll}17 & 20 & 56.7 \%\end{array}$

Ketan G 2013

215

$12 \quad 15 \quad 43.3 \%$

$0.04[0.01,0.23] 2013$

Total $(\mathbf{9 5} \% \mathrm{Cl})$

35

$35100.0 \%$

$0.04[0.01,0.27] 2013$

Total events

29

Heterogeneity: $\mathrm{Chi}^{2}=0.01, \mathrm{df}=1(\mathrm{P}=0.92) ; \mathrm{I}^{2}=0 \%$

Test for overall effect: $Z=4.95$ ( $P<0.00001)$

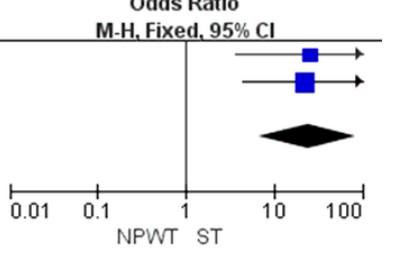

Odds Ratio

$0.04[0.01,0.15]$

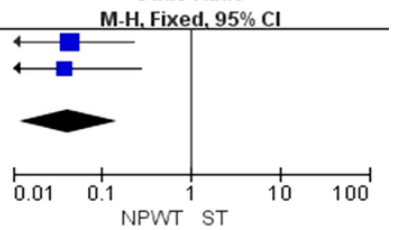

\section{Figure 5}

Forest plot demonstrating the pooled results of the included RCTs with respect to the Disability Rating Index (DRI) (a), EQ-5D, (b) the rate of length of hospital stay $<1$ month (c) and length of hospital stay $>1$ month (d). 
NPWT

ST

Events

Study or Subgroup

\subsubsection{Amputation}

Stannard JP 2009

Virani SR 2016

Costa ML 2018

Subtotal $(95 \% \mathrm{CI})$

Total events

Heterogeneity: $\mathrm{Chi}^{2}=1.19, \mathrm{df}=2(P=0.55) ; \mathrm{I}^{2}=0 \%$

Test for overall effect: $Z=0.33(P=0.74)$

\subsubsection{Nonunion}

Costa ML 2018

Tahir M 2020

Subtotal $(\mathbf{9 5} \% \mathrm{Cl})$

Total events

Heterogeneity: $\mathrm{Chi}^{2}=2.74, \mathrm{df}=1(\mathrm{P}=0.10) ; \mathrm{I}^{2}=64 \%$

Test for overall effect: $Z=0.09(P=0.93)$

Total $(95 \% \mathrm{Cl})$

Total events

\section{8}

$757 \quad 100.0 \%$

$0.96[0.66,1.40]$

Heterogeneity: $\mathrm{Chi}^{2}=4.05, \mathrm{df}=4(\mathrm{P}=0.40) ; \mathrm{I}^{2}=1 \%$

Test for overall effect: $Z=0.20(P=0.84)$

Test for subaroun differences: $\mathrm{Chi}^{2}=0.07 . \mathrm{df}=1(\mathrm{P}=0.78) . \mathrm{I}^{2}=0 \%$
Odds Ratio

M-H, Fixed, 95\% Cl Year

$3.59[0.17,78.04] 2009$

$0.38[0.02,9.55] 2016$

$0.68[0.19,2.46] 2018$

$0.84[0.30,2.38]$
Odds Ratio

M-H. Fixed, $95 \% \mathrm{Cl}$

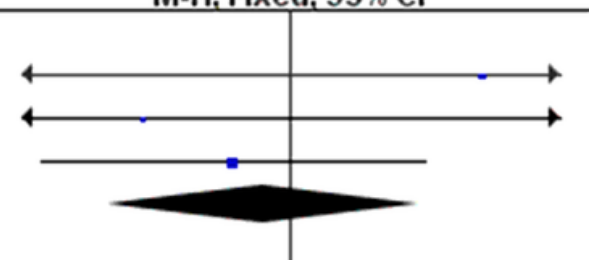

Figure 6

Forest plot demonstrating the complications of the included RCTs. 